\title{
Clostridium difficile in Dolj County (Romania) - surveillance information 2015 to 2016
}

\author{
Livia Dragonu1,2, Augustin Cupsa ${ }^{1,2}$, Ana Bobarnac ${ }^{3}$, Ludmila Prunariư ${ }^{3}$, \\ Iulian Gheorghe Diaconescu ${ }^{1,2}$ \\ ${ }^{1}$ University of Medicine and Pharmacy, Craiova, Romania \\ ${ }^{2}$ Hospital for Infectious Diseases and Pneumology "Victor Babes", Craiova, Romania \\ ${ }^{3}$ Public Health Department Dolj, Romania
}

\begin{abstract}
Objectives. The paper aims epidemiological characteristics of the nosocomial infection with Clostridium difficile (CDIn) based on surveillance data reported by medical facilities in Dolj County (Romania).

Methods. We performed a retrospective study (January 2015 - December 2016) of 506 files with declaration of cases of $C$. difficile infections (CDI) recorded in adults.

Results. CDIn represented $83.7 \%$ of the cases of CDI, an increase from 13.8 cases/month in 2015 to 21.5 cases/month in 2016 . The symptoms began after discharge in $46.6 \%$ of cases and during hospitalization for $53.4 \%$ of the reported cases. The illness origin was in $47.8 \%$ of cases in a medical unit different from the reporting one. The number of CDIn was higher in the infectious disease wards $(0.73 \mathrm{cases} / \mathrm{bed} / \mathrm{year})$ and intensive care $(0.3 \mathrm{cases} / \mathrm{bed} / \mathrm{year})$. The main risk factors were the antibiotics administration (87.1\%) and the age over 60 (69.3\% of cases). The lethality by CDIn was $2.1 \%$ and in $5.7 \%$ of the cases, death being produced by aggravation of the associated pathology.

Conclusions. The implementation of the CDI surveillance contributed to Dolj County to improve monitoring and identification of the risk factors associated to this disorder.
\end{abstract}

Keywords: Clostridium difficile, nosocomial infection, surveillance data

\begin{abstract}
Abbreviations
CDI: Clostridium difficile infection;

CDIn: Clostridium difficile nosocomial infection;

CDIc: Infection with Clostridium difficile Community;

CDIi: Infection with Clostridium difficile indefinite;

RR: relative risk; 95\% CI: 95\% confidence interval
\end{abstract}

\section{INRODUCTION}

The emergence of Clostridium difficile infection (CDI) has become a worldwide important cause for nosocomial and postantibiotics diarrhea. The rise in CDI cases has been observed since 2002 in North America and Canada later the spread of this disease being reported in most of the European countries (1). In Romania there were registered cases of CDI beginning with
2011 (2), but the raising incidence was difficult to estimate in the absence of a national surveillance system.

Since July 2014, the CDI surveillance in the health facilities with beds, was introduced in Romania, carried out under the coordination of the National Institute of Public Health (3), with 2970 CDI cases being reported between July and December 2014 (72.2\% of nosocomial origin) (4). 
In this context, we considered important to study some epidemiological characteristics of CDI based on the surveillance data reported to administrative territorial unit of Romania (Dolj County). The paper aims CDI cases, determining their share of the total CDI, the profile of the reporting medical departments, the infection origin, the onset of the clinical manifestations in relation to hospitalization, the cases evolution and the assessment of the risk factors identified in the illness occurrence.

\section{MATERIAL AND METHOD}

\section{Definitions}

According to the place of the infection, CDI is classified into 3 types: nosocomial CDI (CDIn) Community CDI (CDIc) and indefinite CDI (CDIi). CDIn may have the debut inside the hospital (less than 48 hours after admission) or in the community (within 28 days after discharge) $(3,5)$.

\section{Material}

The material is composed by the 2-year retrospective study (January 2015 - December 2016) of the declaration files of the CDI cases reported by medical facilities in Dolj County. The CDI cases have originated in 7 medical sections, totaling 447 beds, 7 surgical sections, totaling 528 beds, an intensive care unit with 55 beds and 2 sections with infectious diseases with 130 beds. The case definition for CDI was applied to all the reported cases, including in the trial only adults over 18 years old.

There were analyzed 506 non-repetitive cases with primary CDI confirmed by lab (465 cases, by immunoenzymatic test for toxin A and/or B and 41 cases by PCR gene identification for $C$. difficile toxins in the stool).

The data obtained from the CDI declaration files were: the type of CDI (CDIn, CDIc, CDIi), demographic data, the profile of the department that reported the disease, the origin of the CDI in the reporting polling section or in other medical reporting section, the time of onset of symptoms during hospitalization or after discharge, the evolution, the risk factors (medication administration antacids, chemotherapy treatment, recent gastrointestinal surgery, immunosuppression, contact with a known case of CDI, antibiotic treatment).

\section{Data analysis}

For the statistical analysis it was used the determination of the relative risk (RR) with the interval of confidence (IC) $95 \%$. RR with greater value than indicated a causal correlation between some risk factors and the disease. For the situation when RR was $\geq 1$ we applied the square Chi test, considering that there is a statistically significant correlation for the value $\mathrm{p}<0.05$. To determine the average annual number of cases of CDIn/hospital bed, according to the profile of the medical departments we divided the annual average of CDIn cases registered to the number of beds in those sections.

\section{RESULTS}

\section{The number of cases reported CDIn}

In the studied period there were recorded 506 cases of CDI, of which 424 (83.7\%) had nosocomial cause, 57 (11.2\%) were from the community and 22 (4.9\%) were undetermined (Table 1).

TABLE 1. Annual distribution of cases by type of CDI

\begin{tabular}{|c|c|c|c|c|c|}
\hline \multirow[t]{2}{*}{$\begin{array}{l}\text { Type } \\
\text { of CDI }\end{array}$} & \multicolumn{2}{|c|}{$\begin{array}{c}\text { Year (number } \\
\text { of cases) }\end{array}$} & \multirow{2}{*}{$\begin{array}{c}\text { Total } \\
\text { Number of } \\
\text { cases }(\%)\end{array}$} & \multirow[t]{2}{*}{$\mathrm{RR}(95 \% \mathrm{Cl})$} & \multirow[t]{2}{*}{$\mathrm{p}$} \\
\hline & 2015 & 2016 & & & \\
\hline CDIC & 14 & 43 & $57(11.2)$ & \multirow{3}{*}{$\begin{array}{c}5.17 \\
(4.22 \text { to } 6.32)\end{array}$} & \multirow[b]{3}{*}{$<0.0001$} \\
\hline CDli & 8 & 17 & 25 (4.9) & & \\
\hline CDIn & 166 & 258 & $424(83.7)$ & & \\
\hline Total & 188 & 318 & $506(100)$ & & \\
\hline
\end{tabular}

CDIn held a statistically significant weight in the total recorded number of CDI $(\mathrm{RR}=5.17$, $95 \% \mathrm{CI}=4.22$ to $6.32, \mathrm{p}<0.0001$ ). The number of CDI cases increased from a monthly average 
of 15.6 cases/month in 2015 to 26.5 cases/ month in 2016.

The cases growth was carried out mainly by CDIn, their monthly average increased from 13.8 cases/month in 2015 to 21.5 cases/month in 2016.

\section{The CDIn distribution after the medical sections profile}

The number of CDIn/hospital bed/year recorded the highest value in the sections with infectious diseases profile ( 0.73 cases/bed/year) and in the intensive care units (0.3 cases/bed/ year). In the sections for infectious diseases the cases from other reporting units were CDIn 0.64 cases/bed/year (Table 2).

CDIn originated in the reporting unit did not differ between the sections with medical profile, surgical and infectious diseases $(0.08$ to 0.09 CDIn/bed/year). The intensive care unit recorded the highest number of cases from the same CDIn with the origin in the same reporting unit (0.24 ICDn/bed/year).

\section{The onset of the CDIn symptoms in relation with hospitalization}

The CDIn symptoms appeared 48 hours after hospitalization in 226 cases (53.4\%) and less than 4 weeks after discharge in 198 cases (46.6\%), with no statistically significant difference between hospital or community-onset forms of ICDn (RR $=1.14,95 \% \mathrm{CI}=1.30$ to 1.91 , $\mathrm{p}=0.05$ ) in Table 3 .

In CDIn with hospital-onset the symptoms occurred within the first 14 days after admission 178 cases (78.8\%) and 15 days after hospitalization in 48 cases $(21.2 \%)(\mathrm{RR}=3.70,95 \%$ $\mathrm{CI}=2.85$ to $4.80, \mathrm{p}<0.0001$ ). In CDIn with communitary onset the symptoms appeared in the first 14 days after discharge in $72.7 \%$ of cases and 15 - 28 days after discharge for $27.3 \%$ of the cases $(\mathrm{RR}=2.66,95 \% \mathrm{CI}=2.09$ to $3.39, \mathrm{p}$ $<0.0001$ ) (Table 3).

\section{Risk factors for developing CDIn}

The demographic data (age, area of origin, sex) and the factors known as favoring the emer-

TABLE 2. Distribution following the CDIn origin and number of cases of CDIn / hospital bed / year

\begin{tabular}{|l|c|c|c|c|c|}
\hline Profile section & Intensive care & Surgical care & Medical care & Infec ous Diseases & Total \\
\hline Origin of CDIn & & & & & \\
Number of cases in 2 years & & & & & \\
- the repor ng sec on & 27 & 92 & 87 & 25 & 221 \\
- in other sec ons & 6 & 3 & 19 & 165 & 203 \\
- total & 33 & 95 & 106 & 190 & 424 \\
\hline Number of beds & 55 & 528 & 447 & 130 & 1160 \\
\hline Number CDIn/bed/year & & & & & \\
- the repor ng sec on & 0.25 & 0.08 & 0.09 & 0.09 & 0.09 \\
- in other sec ons & 0.05 & 0.01 & 0.02 & 0.64 & 0.08 \\
- total & 0.3 & 0.09 & 0.11 & 0.73 & 0.17 \\
\hline
\end{tabular}

TABLE 3. The interval of CDIn symptoms onset in relation to hospitalization ( $n=424$ cases)

\begin{tabular}{|c|c|c|c|c|c|}
\hline Debut CDIn & $\begin{array}{c}\text { Number of } \\
\text { days }\end{array}$ & $\begin{array}{c}\text { Number of cases } \\
(\%)\end{array}$ & $\begin{array}{c}\text { Total } \\
\text { Number of cases }\end{array}$ & $\mathrm{p}$ & RR (95\% Cl) \\
\hline \multirow{4}{*}{$\begin{array}{l}\text { DURING ADMISSION } \\
\text { (in hospital) }\end{array}$} & $2-7$ & $85(37.6)$ & \multirow{4}{*}{226} & \multirow{7}{*}{$=0.05$} & \multirow{7}{*}{$\begin{array}{c}1.14 \\
(1.30 \text { to } 1.91)\end{array}$} \\
\hline & $8-14$ & $93(41.2)$ & & & \\
\hline & $15-30$ & $33(14.6)$ & & & \\
\hline & $31-68$ & $15(6.6)$ & & & \\
\hline \multirow{3}{*}{$\begin{array}{l}\text { AFTER DISCHARGE } \\
\text { (communitary) }\end{array}$} & $0-7$ & $85(42.9)$ & \multirow{3}{*}{198} & & \\
\hline & $8-14$ & $59(29.8)$ & & & \\
\hline & $15-28$ & $54(27.3)$ & & & \\
\hline
\end{tabular}


TABLE 4. Evaluation of favoring factors CDIn for the the studied cases $(n=424)$

\begin{tabular}{|l|c|c|c|c|}
\hline Characteristics of patients & $\begin{array}{c}\text { Number } \\
\text { of cases }\end{array}$ & $\begin{array}{c}\% \text { of } \\
\text { total }\end{array}$ & $\mathrm{p}^{*}$ & $\mathrm{RR}(95 \% \mathrm{Cl})$ \\
\hline Age over 60 years & 294 & 69.3 & $<0.0001$ & $2.26(1.93$ to 2.64$)$ \\
\hline Provenance urban environment & 228 & 53.7 & 0.02 & $1.16(1.01$ to 1.33$)$ \\
\hline Female & 217 & 51.1 & 0.49 & 1.04 (0.91 to 1.19$)$ \\
\hline Contact with a case of CDI & 191 & 45.1 & & 0.81 (0.71 to 0.93) \\
\hline An bio c treatment & 369 & 87.1 & $<0.0001$ & 6.70 (5.22 to 8.60$)$ \\
\hline Antacid medica on & 135 & 31.8 & & $0.46(0.40$ to 0.54$)$ \\
\hline Immunocompromised & 81 & 19.1 & & $0.23(0.19$ to 0.28$)$ \\
\hline Surgery & 95 & 22.4 & & $0.28(0.24$ to 0.34$)$ \\
\hline Diges ve surgery in 14 days & 45 & 10.6 & & $0.29(0.24$ to 0.35$)$ \\
\hline
\end{tabular}

* applied for the situations when $\mathrm{RR} \geq 1$

gence of CDIn were ranked according to the significant risk they had in the occurrence of the illness (Table 4).

In 294 cases $(69.3 \%$ of total) the patients age was 60 , this result having a statistical significance $(\mathrm{RR}=2.26,95 \% \mathrm{CI}=1.93$ to $2.64, \mathrm{p}<0.0001)$ for CDIn appearance.

Of all the CDIn cases, $51.1 \%$ (217 cases) were female and $48.9 \%$ (207 cases) were men, the gender difference being not statistically significant $(\mathrm{RR}=1.04,95 \% \mathrm{CI}=0.91$ to $1.19, \mathrm{p}=0.49)$.

From the percentage point of view it was observed a slight predominance of the cases from the urban areas than from the rural $(53.7 \%$ versus $46.3 \%$ ), with no statistically significant difference $(\mathrm{RR}=1.16,95 \% \mathrm{CI}=1.01$ to $1.33, \mathrm{p}=$ 0.02 ) after the patients area of origin.

The contact with a case of CDI during the hospitalization was confirmed in 25 cases (5.8\%) and found to be possible in 166 cases (39.1\%). In 233 cases (54.9\%) the contact with a CDI case remained unknown.

The antibiotic treatment was administered to $87.1 \%$ of the studied CDIn cases (RR $=6.70,95 \%$ $\mathrm{CI}=5.22$ to 8.60 ), and the antacid medication to $31.8 \%$ of the cases $(\mathrm{RR}=0.46,95 \% \mathrm{CI}=0.40$ to $0.54)$. The digestive surgery performed less than 14 days prior to $\mathrm{CDIn}$ onset $(\mathrm{RR}=0.29,95 \% \mathrm{CI}=$ 0.24 to 0.35 ) accounted for $47.3 \%$ of the total surgeries.

The severe immunocompromised disease (13.1\% of cases) in patients receiving chemotherapy ( $4.4 \%$ of cases) or immunosuppressive therapy (1.6\% of cases) accounted for $19.1 \%$ of the cases with CDIn ( $\mathrm{RR}=0.23,95 \% \mathrm{CI}=0.19$ to $0.28)$.

\section{The cases evolution}

Out of the 424 cases of CDIn, 105 patients (24.8\%) were discharged healed, 286 (67.4\%) discharged with improved clinical status and 33 patients $(7.8 \%)$ died. The deaths were due directly to CDIn in 9 cases $(2.1 \%)$ and in 24 cases $(5.7 \%)$ to the aggravation of the associated pathology.

\section{DISCUSSIONS}

CDIn held a significant share (83.7\%) of the reported CDI in Dolj County. Gastmeier (2009) found using data from the German system monitoring of the CDI that $73 \%$ of the cases were nosocomial ones with differences of incidence between hospitals based on the diagnostic procedures and participation in the surveillance system (6).

A particular aspect detached by our study (Table 2) was linked to the fact that $47.8 \%$ of CDIn (203 of 424 cases) originated in a medical facility different from the reporting one. The profile of the infectious diseases recorded the highest number of CDIn, the origin of the infection being in 165 of 190 cases (86.8\%) in other sections from where the patient was transferred or discharged. This situation is explained by the fact that in Romania there is a national network 
of Infectious Diseases regional hospitals where they are treating patients with CDI from the community or acquired in other general hospitals (2). CDIn with the origin in the reporting unit recorded a total of 2.6 times greater $(0.24$ versus 0.09 ) in the intensive care unit than in the medical, surgical or infectious diseases specialized units. The increased risk for the CDIn occurrence is correlated with favoring specific factors for intensive care unit (7).

CDI with communitary-onset accounted for $46.6 \%$ of CDIn, challenging an epidemiologically important aspect related to $C$. difficile infection which becomes manifest clinically in patients after being discharged. In CDIn with hospital onset we found that in $78.8 \%$ of the cases the illness occurred within 14 days after admission. The onset of the symptoms was recorded in $37.6 \%$ of cases even after a short period of hospitalization (2-7 days). According Clabots CR (8) the CDIn risk increases with the length of the hospitalization, the infection rate for $C$. difficile being estimated at $13 \%$ of the patients with admission up to 2 weeks and $50 \%$ of the patients with prolonged hospitalization over four weeks.

The contact with a case of CDI was mentioned only in $45.1 \%$ of patients of our study, the source is unknown in $54.9 \%$ of the cases that acquired the infection by a nosocomial way.

The sources of infection can be asymptomatic carriers of $C$. difficile in chair (9) which transmit the pathogen to other patients in the same hospital.

The main contributing factors in the appearance of the CDIn were the age over 60 (69.3\% of cases) and the antibiotics intake $(87.1 \%$ of the cases). The risk of developing ICD is dominated by the exposure to the antibiotic, it is increased in the first month following the discontinuation of the treatment and decreasing in the next 1-3 months (10). Correlating this aspect with the interval of the communitary-onset of the CDIn occurrence, in our study, the highest risk of CDIn appearance after the antibiotic treatment dis- continuation was recorded in the first 14 days after the hospital discharge. The age of 65 years is confirmed as a factor for CDI appearance and for the unfavorable evolution of the disease (11, 12).

The antacid medication administration (31.8\%), immunosuppression (19.1\%) and abdominal surgery (10.6\%) held in our study less weight in predisposing factors for CDIn. The antacid medication was associated with increased CDI risk, but Kwok (13) considers that actually the association with the antibiotics determines this outcome. Immunosuppressed patients are susceptible to infection with $C$. difficile, both by the action of chemotherapeutic agents and immunosuppressive ones and by repeated exposure to antibiotic treatments due to frequent infections (14).

The direct lethality by CDIn in the studied cases was $2 \%$ and with aggravating potential to death in $6 \%$ of CDIn cases. The data provided by D. Gravel (15) mention similar results, indicating a direct lethality of $2.2 \%$ related to CDI and an indirect one of 3.6\%, with an overall mortality rate of $5.7 \%$. Zilberberg MD (16) conducted an analysis on several studies on global lethality by CDI in the day 30 of hospitalization and found variations in the results between 8 and $37.2 \%$.

\section{CONCLUSIONS}

1. Applying the surveillance program in Dolj County since 2014 was an important step to monitor the CDI that occurred both during hospitalization and after discharge.

2. CDI had mainly a nosocomial cause, registering an increase of the cases. CDIn greater risk was associated with the antibiotic treatment, with the age over 60 years and with the hospitalization in intensive care.

3. The high percentage CDIn occurred after discharge or originating in one medical unit different from the medical reporting one highlighted important epidemiological issue related to $C$. difficile circuit between the medical departments and the community. 
The CDI epidemiology continues to present changes requiring to maintain an increased at- tention for the prevention of this disease with aggravating potential for the patient evolution.

Conflict of interest: none declared Financial support: none declared

\section{REFERENCES}

1. Loo V.G., Poirier L., Miller M.A. et al. A predominantly clonal multi-institutional outbreak of Clostridium difficile-associated diarrhea with high morbidity and mortality. N Engl J Med. 2005; 353: 2442-9

2. Rafila A., Indra A., Popescu G.A. et al. Occurrence of Clostridium difficile infections due to PCR ribotype 027 in Bucharest, Romania. J Infect Dev Ctries. 2014; 8(6):694-698.

3. Centrul Național de Supraveghere şi Control al Bolilor Transmisibile. Metodologia de supraveghere a infecției cu Clostridium difficile; accessed at (http://www.cnscbt.ro/index.php/metodologii/infectiinosocomiale/194-metodologie-supraveghere-icd-2014/file)

4. Centrul Național de Supraveghere şi Control al Bolilor Transmisibile. Analiza evoluției bolilor transmisibile aflate în supraveghere, raport pentru anul 2014; accessed at (http://www.cnscbt.ro/index.php/ rapoarte-anuale/548-analiza-evolutiei-bolilor-transmisibile-aflate-insupraveghere-raport-pentru-anul-2014/file 65)

5. McDonald L.C., Coignard B., Dubberke E. et al. Ad Hoc Clostridium difficile Surveillance Working Group. Recommendations for surveillance of Clostridium difficile-associated disease. Infect Control Hosp Epidemiol. 2007; 28:140-5.

6. Gastmeier P., Weitzel-Kage D., Behnke M., Eckmanns T. Surveillance of Clostridium difficile-associated diarrhea with the German nosocomial infection surveillance system KISS (CDADKISS). Int J Antimicrob Agents. 2009; 33 (Suppl 1):S19-S23.

7. Riddle D.J., Dubberke E.R. Clostridium difficile infection in the intensive care unit. Infect Dis Clin North Am. 2009 Sep; 23(3):727-43.

8. Clabots C.R., Johnson S., Olson M.M. et al. Acquisition of Clostridium difficile by hospitalized patients: evidence for colonized new admissions as a source of infection. J Infect Dis.1992; 166 (3): 561-7
9. Furuya-Kanamori L., Yakob L., Riley V.T. et al. Asymptomatic Clostridium difficile colonization: epidemiology and clinical implications. BMC Infect Dis. 2015; 15:516

10. Gerding D.N., Young V.B. Clostridium difficile Infection. In: Bennett JE, Dolin R, Blaser MJ (Eds). Mandell, Douglas, and Bennett's Principles and Practice of Infectious Diseases. $8^{\text {th }}$ ed. Philadelphia: Elsevier Saunders, 2014, Vol 1: 2747-2749

11. Laza R., Jurac R., Crişan A. et al. Clostridium difficile in western Romania: unfavourable outcome predictors in a hospital for infectious diseases. BMC Infect Dis. 2015; 15:141-148

12. Vardakas K.Z., Konstantelias A.A., Loizidis G. et al. Risk factors for development of Clostridium difficile infection due to BI/NAP1/027 strain: a meta-analysis. Int J Infect Dis. 2012; 16: e768-e773.

13. Kwok C.S., Arthur A.K., Anibueze C.I. et al. Risk of Clostridium difficile infection with acid suppressing drugs and antibiotics: meta-analysis. Am J Gastroenterol. 2012; 107:1011-1019.

14. Schaier M., Wendt C., Zeier M., Ritz E. Clostridium difficile diarrhoea in the immunosuppressed patient - update on prevention and management. Nephrol Dial Transplant. 2004; 19: 2432-36

15. Gravel D., Miller M., Simor A. et al. Health Care-Associated Clostridium difficile Infection in Adults Admitted to Acute Care Hospitals in Canada: a Canadian Nosocomial Infection Surveillance Program Study. Clin Infect Dis. 2009; 48 (5):568-76

16. Zilberberg M.D., Shorr A.F., Micek S.T. et al. Clostridium difficileassociated disease and mortality among the elderly critically ill. Crit Care Med. 2009; 37:2583-9. 